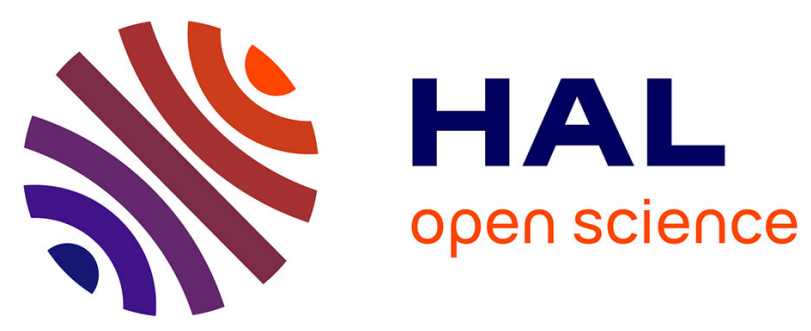

\title{
Performance and Transport Analysis of Vertically Stacked p-FET SOI Nanowires
}

Bruna Cardoso Paz, Marcelo Antonio Pavanello, Mikael Casse, Sylvain Barraud, Gilles Reimbold, Maud Vinet, Olivier Faynot

\section{- To cite this version:}

Bruna Cardoso Paz, Marcelo Antonio Pavanello, Mikael Casse, Sylvain Barraud, Gilles Reimbold, et al.. Performance and Transport Analysis of Vertically Stacked p-FET SOI Nanowires. 2017 Joint International EUROSOI Workshop and International Conference on Ultimate Integration on Silicon (EUROSOI-ULIS), Apr 2017, Athènes, Greece. 10.1109/ULIS.2017.7962606 cea-01974216

\section{HAL Id: cea-01974216 https://hal-cea.archives-ouvertes.fr/cea-01974216}

Submitted on 8 Jan 2019

HAL is a multi-disciplinary open access archive for the deposit and dissemination of scientific research documents, whether they are published or not. The documents may come from teaching and research institutions in France or abroad, or from public or private research centers.
L'archive ouverte pluridisciplinaire $\mathbf{H A L}$, est destinée au dépôt et à la diffusion de documents scientifiques de niveau recherche, publiés ou non, émanant des établissements d'enseignement et de recherche français ou étrangers, des laboratoires publics ou privés. 


\section{Performance and Transport Analysis of Vertically Stacked p-FET SOI Nanowires}

\author{
Bruna Cardoso Paz and Marcelo Antonio Pavanello \\ Department of Electrical Engineering \\ Centro Universitário da FEI \\ São Bernardo do Campo, Brazil \\ bcpaz@fei.edu.br
}

\begin{abstract}
This work presents the performance and transport characteristics of vertically stacked p-MOSFET SOI nanowires (NWs) with inner spacers and epitaxial growth of SiGe raised source/drain. Electrical characterization is performed for NWs with [110] and [100] channel orientations, as a function of both fin width (W Fin) and channel length (L). Results show a good electrostatic control and reduced short channel effects (SCE) down to $15 \mathrm{~nm}$ gate length. Improved effective mobility is obtained for [110]-oriented NWs due to higher sidewall mobility contribution.
\end{abstract}

Keywords-performance; transport; electrical characterization; vertically stacked nanowire; SOI MOSFET; channel orientation.

\section{INTRODUCTION}

Multiple gate transistors have been designed to improve the electrostatic control of the gate over the charges in the channel, allowing stronger immunity against short channel effects [1]. Since higher electrostatic coupling is obtained increasing the number of gates and reducing the distance among them, triple gate (3G) and Gate-All-Around (GAA) MOSFETs have demonstrated to outperform short channel FinFETs, attracting interest of both scientific community and semiconductor industry [2].

Nanoscale multiple gate MOSFETs called nanowires, characterized by thin silicon thickness and narrow fin width, have shown to be a good alternative to FinFET technology for the continuity of the CMOS roadmap due to their great performance and scalability [3], [4].

To fulfill higher drive current requests imposed by the International Technology Roadmap for Semiconductors (ITRS), the performance of multiple gate structures have been improved through the development of new technologies and implementation of different materials and process techniques, such as mechanical stress and rotated substrates. While the use of compressive and tensile stress can enhance holes and electrons mobility, respectively [5], [100]-orientated channel can boost n-type NWs current due to higher electrons mobility along (100) sidewalls [6].

Recently, vertically stacked NWs have been successfully fabricated due to advanced process developments. These devices combine reduced SCE and improved on-state current ( $\left.\mathrm{I}_{\mathrm{ON}}\right)$ due to higher device aspect ratio, as the overall channel

\author{
Mikaël Cassé, Sylvain Barraud, Gilles Reimbold, \\ Maud Vinet and Olivier Faynot \\ Département des Composants Silicium - SCME/LCTE \\ CEA-LETI Minatec \\ Grenoble, France
}

width $\left(\mathrm{W}_{\mathrm{eff}}\right)$ is increased and proportional to the number of beams [7]-[9].

In this work, we present the performance and transport of vertically stacked p-FET SOI NWs fabricated with inner spacers and $\mathrm{SiGe}$ raised source/drain [9]. The analysis is performed as a function of both $\mathrm{W}_{\text {FIN }}$ and $\mathrm{L}$, for $\mathrm{NWs}$ orientated along [110] and [100] directions. Electrical characterization is performed from $\mathrm{I}-\mathrm{V}$ and $\mathrm{C}-\mathrm{V}$ curves to evaluate $\mathrm{I}_{\mathrm{ON}} / \mathrm{I}_{\mathrm{OFF}}$ behavior, gate-to-channel capacitance $\left(\mathrm{C}_{\mathrm{GC}}\right)$, effective oxide thickness $(\mathrm{EOT})$, threshold voltage $\left(\mathrm{V}_{\mathrm{TH}}\right)$ rolloff, subthreshold slope $(\mathrm{S})$, DIBL, series resistance $\left(\mathrm{R}_{\mathrm{S}}\right)$ and effective mobility $\left(\mu_{\mathrm{eff}}\right)$.

\section{DEVICES ChARACTERISTICS}

Vertically stacked NWs with two levels have been fabricated at CEA-LETI, starting from SOI wafers with $145 \mathrm{~nm}$ buried oxide thickness and using a replacement metal gate (RMG) process. TEM images of the cross section (a) and the longitudinal section (b) of the studied stacked-NWs MOSFETs are presented in Fig. 1. It is observed that the wire at the bottom presents a $\Omega$-shaped gate while the wire at the top is GAA. Both levels have a $10 \mathrm{~nm}$ thick $\mathrm{Si}$ channel and $\mathrm{Si}_{0.7} \mathrm{Ge}_{0.3}: \mathrm{B}$ raised source/drain have been used in order to induce a compressive strain of up to $1 \%$ in both top and bottom channels [9]. The transistors have been fabricated along two different crystallographic orientations, [110] and [100], and present a gate stack composed by $\mathrm{HfO}_{2} / \mathrm{TiN} / \mathrm{W}$. Further fabrication details of the stacked-NWs studied in this work can
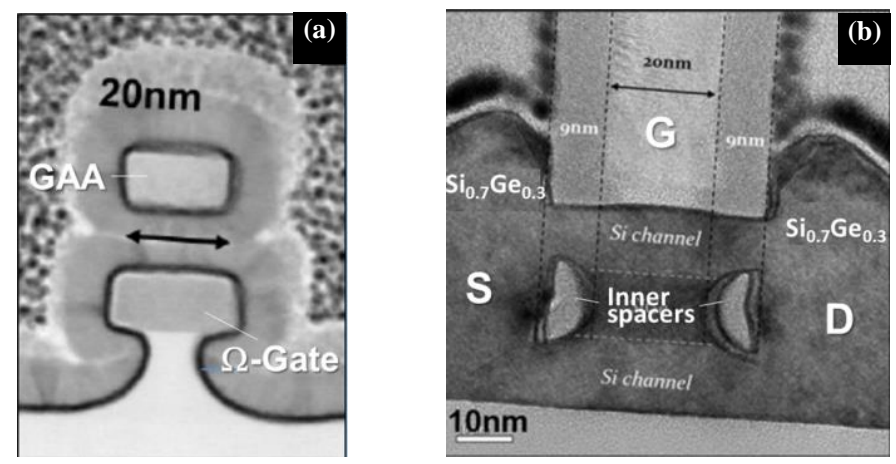

Fig.1. Vertically stacked SOI NW cross section (a) and longitudinal section (b) TEM images. 


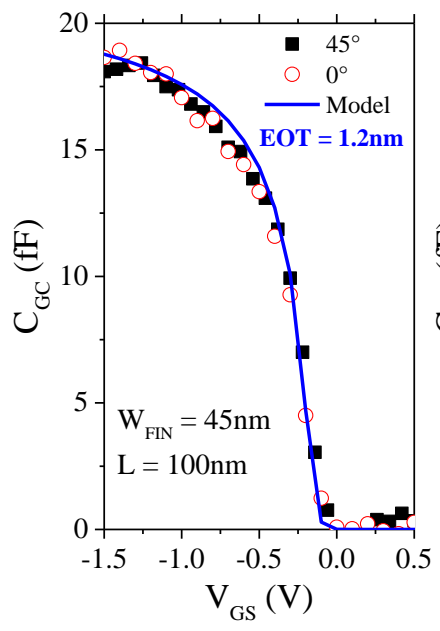

(b)

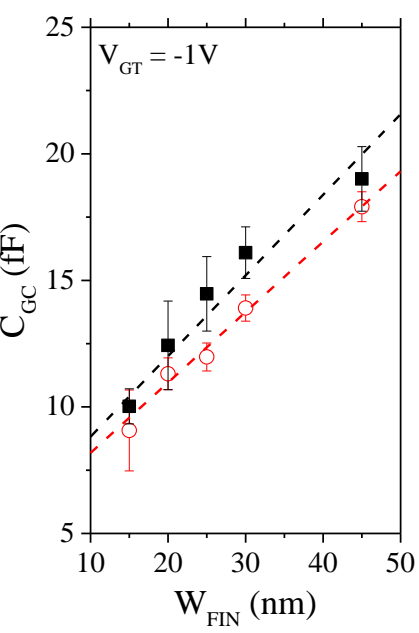

(b)
Fig.2. $\mathrm{C}_{\mathrm{GC}}$ as a function of $\mathrm{V}_{\mathrm{GS}}$ (a) and $\mathrm{C}_{\mathrm{GC}}$ as a function of $\mathrm{W}_{\mathrm{FIN}}$ (b) for [110] and [100]-NWs, $\mathrm{L}=100 \mathrm{~nm}$. $\mathrm{C}_{\mathrm{GC}}$ modelling allowed EOT extraction of $1.2 \mathrm{~nm}$

be found in [9].

In order to extract the EOT resulted from the gate stack deposition after RMG process, capacitance measurements were performed and compared to results obtained from a PoissonSchrödinger solver considering quantum confinement effects for FDSOI MOSFETs. Fig. 2.a presents $\mathrm{C}_{\mathrm{GC}}$ as a function of $\mathrm{V}_{\mathrm{GS}}$ for [110]- and [100]-NWs, $\mathrm{W}_{\mathrm{FIN}}=45 \mathrm{~nm}$ and $\mathrm{L}=100 \mathrm{~nm}$. The solid line indicate the modelled result considering EOT of $1.2 \mathrm{~nm}$. After fitting the experimental $\mathrm{C}-\mathrm{V}$ curves, $1.2 \mathrm{~nm}$ of EOT has been extracted for both transport orientations. Fig. 2.b presents $\mathrm{C}_{\mathrm{GC}}$ as a function of $\mathrm{W}_{\mathrm{FIN}}$ for NWs biased at the same gate voltage overdrive $\left(\mathrm{V}_{\mathrm{GT}}=\mathrm{V}_{\mathrm{GS}}-\mathrm{V}_{\mathrm{TH}}=-1 \mathrm{~V}\right)$. The linear behavior, highlighted by the dashed lines, allows to conclude that EOT is sustained with $\mathrm{W}_{\text {FIN }}$ scaling and channel orientation, indicating uniform and well controlled gate stack deposition process.

\section{RESULTS AND DISCUSSION}

Fig. 3 presents the normalized drain current $\left(\mathrm{I}_{\mathrm{DS}} \mathrm{L}\right)$ as a function of the gate voltage $\left(\mathrm{V}_{\mathrm{GS}}\right)$ for [110] $\left(0^{\circ}\right)$ and [100] $\left(45^{\circ}\right) \mathrm{NWs}$ in multiple finger structures (50 fins), with $\mathrm{L}=$ $30 \mathrm{~nm}$ and $100 \mathrm{~nm}$, at small (a) and strong (b) horizontal electric field, $\mathrm{V}_{\mathrm{DS}}$ of $-40 \mathrm{mV}$ and $-0.9 \mathrm{~V}$, respectively. Higher drain current is observed in [110]-NWs, as expected for p-FETs. Indeed, holes mobility is enhanced in the (110)-oriented sidewalls in comparison to (100) plan [10]. Additionally, the SiGe source and drain induce a uniaxial compressive stress, which may become detrimental in narrow p-NWs with [100]oriented channel. As reported in [11], the longitudinal piezoresistive coefficient of [100]-oriented NWs are lower than zero (see Fig. 5 in [11], where $\pi_{\mathrm{L}, \mathrm{NW}}{ }^{[100]}<0$ ), which degrades even more the holes mobility in such narrow devices. From the logarithmic scaled curves in Fig. 3, it is possible to state that neither by reducing $\mathrm{L}$ from $100 \mathrm{~nm}$ to $30 \mathrm{~nm}$ nor by decreasing $\mathrm{V}_{\mathrm{DS}}$ down to $-0.9 \mathrm{~V}$ significant degradations of the subthreshold characteristics are observed.
Fig. 4 presents $\mathrm{I}_{\mathrm{OFF}} / \mathrm{W}_{\text {eff }}$ as a function of $\mathrm{I}_{\mathrm{ON}} / \mathrm{W}_{\text {eff }}$ (a) and $\mathrm{I}_{\mathrm{ON}} / \mathrm{I}_{\mathrm{OFF}}$ as a function of $\mathrm{W}_{\mathrm{FIN}}(\mathrm{b})$ for $\mathrm{L}=30 \mathrm{~nm}$, at $\mathrm{V}_{\mathrm{DS}}=-$ $0.9 \mathrm{~V}$. I IFF and $\mathrm{I}_{\mathrm{ON}}$ have been extracted at $\mathrm{V}_{\mathrm{GS}}=0$ and $-0.9 \mathrm{~V}$, respectively. For $\mathrm{W}_{\mathrm{FIN}}$ ranging between 15 and $30 \mathrm{~nm}, \mathrm{I}_{\mathrm{ON}} / \mathrm{W}_{\mathrm{eff}}$ of [110]-NWs reaches up to $450 \mu \mathrm{A} / \mu \mathrm{m}$, while $\mathrm{I}_{\mathrm{ON}} / \mathrm{W}_{\text {FIN }}$ can reach up to $2500 \mu \mathrm{A} / \mu \mathrm{m}$ for $\mathrm{W}_{\mathrm{FIN}}=15 \mathrm{~nm}$. The normalization of $\mathrm{I}_{\mathrm{ON}}$ by the effective channel width (calculated by $4 . \mathrm{t}_{\mathrm{Si}}+$ $\left.3 . \mathrm{W}_{\text {FIN }}\right)$ has an important physical meaning, once it aims to calculate the amount of current per unit of length that flows considering all the seven conduction channels formed in both bottom and top wires. On the other hand, the normalization of $\mathrm{I}_{\mathrm{ON}}$ by $\mathrm{W}_{\mathrm{FIN}}$ allows a comparison from the point of view of the top area, highlighting the benefit of increasing $\mathrm{W}_{\text {eff }}$ by stacking

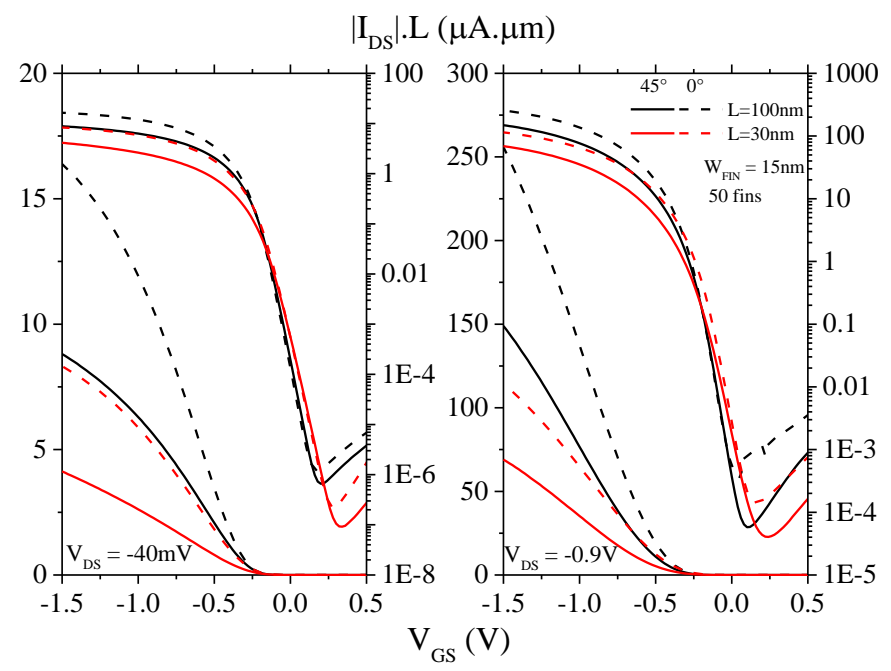

(a)

(b)

Fig.3. $\left|\mathrm{I}_{\mathrm{DS}}\right| \mathrm{L}$ as a function of $\mathrm{V}_{\mathrm{GS}}$ at $\mathrm{V}_{\mathrm{DS}}=-40 \mathrm{mV}$ (a) and $-0.9 \mathrm{~V}$ (b) for [110] and [100]-NWs, $L=100$ and 30nm.

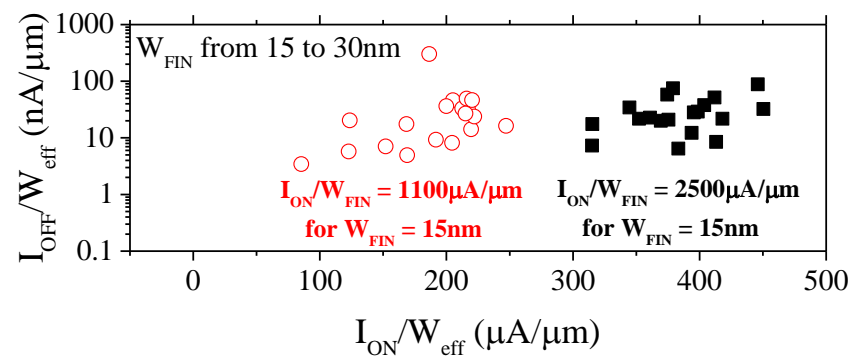

(a)

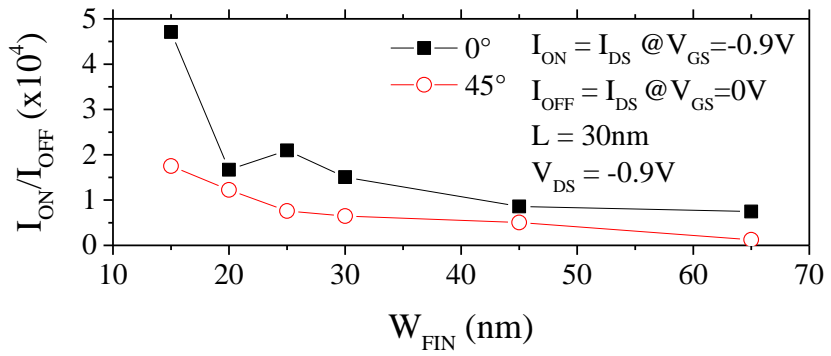

(b)

Fig.4. $\mathrm{I}_{\mathrm{ON}} / \mathrm{I}_{\mathrm{OFF}}$ characteristics for [110] and [100]-NWs with $\mathrm{L}=30 \mathrm{~nm}$, at $\mathrm{V}_{\mathrm{DS}}=-0.9 \mathrm{~V}$. 
2 levels of NWs. Moreover, one can observe similar IOFF for both channel directions and $\mathrm{I}_{\mathrm{ON}} / \mathrm{I}_{\mathrm{OFF}}$ ratio in the order of $\sim 10^{4}$, higher for $0^{\circ} \mathrm{NWs}$ and increasing with $\mathrm{W}_{\mathrm{FIN}}$ reduction.

Fig. 5.a shows the $\mathrm{V}_{\mathrm{TH}}$ behavior with $\mathrm{W}_{\mathrm{FIN}}$ and L, extracted by the second derivative method, at $V_{D S}=-40 \mathrm{mV}$. Improvements for narrower NWs and very small $\mathrm{V}_{\mathrm{TH}}$ roll-off
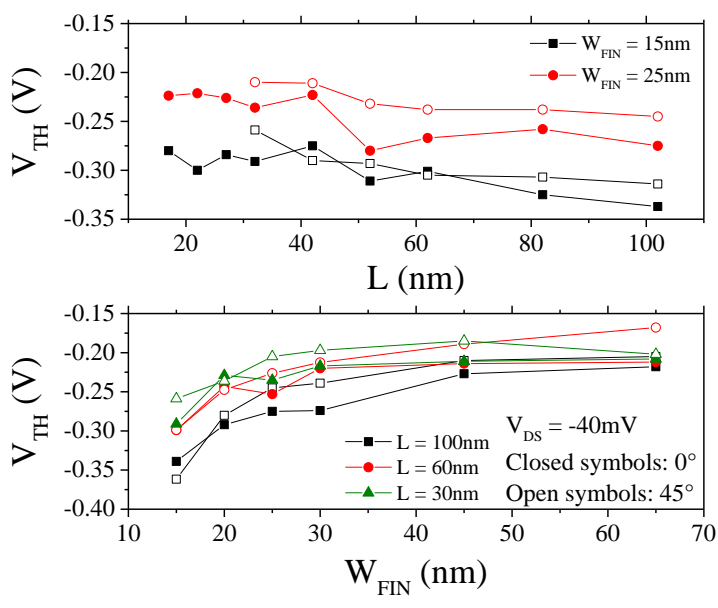

(a)
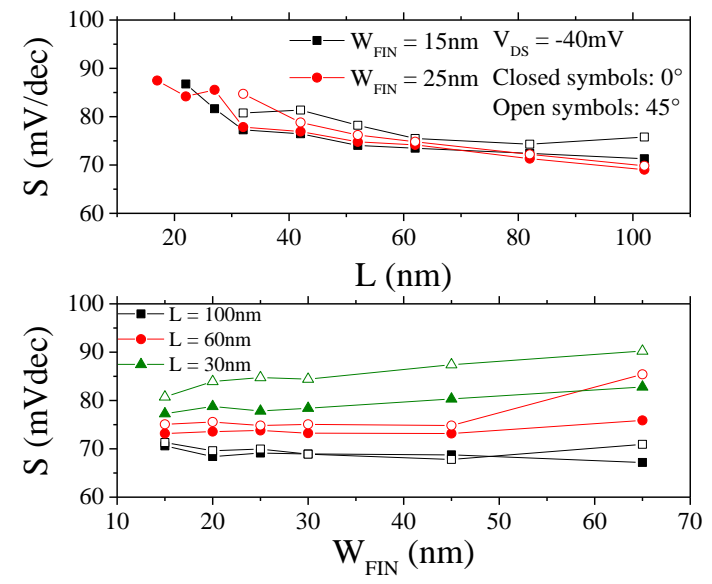

(b)

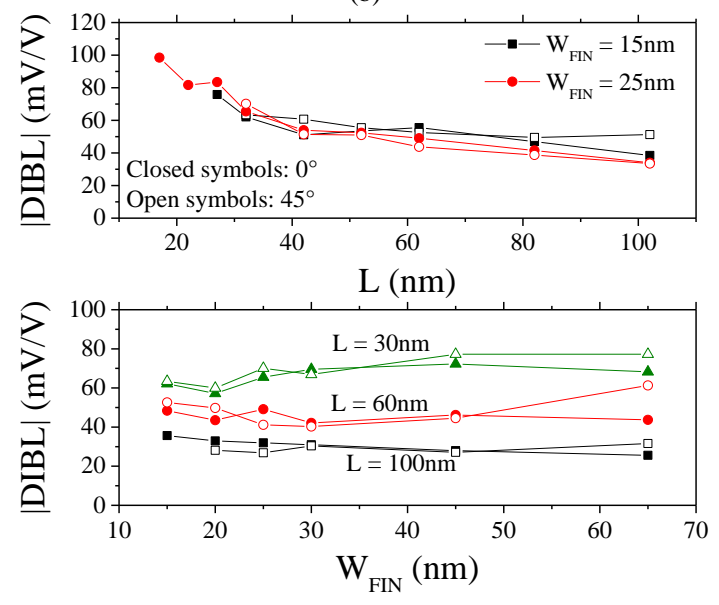

(c)

Fig.5. $\mathrm{V}_{\mathrm{TH}}(\mathrm{a}), \mathrm{S}$ (b) and $|\mathrm{DIBL}|$ (c) as a function of both $\mathrm{L}$ and $\mathrm{W}_{\mathrm{FIN}}$, for several [110] and [100]-NWs, at $\mathrm{V}_{\mathrm{DS}}=-40 \mathrm{mV}$. (lower than $60 \mathrm{mV}$ ) is observed while reducing $\mathrm{L}$ down to 15nm. Figs. 5.b and 5.c show, respectively, $\mathrm{S}$ and $|\mathrm{DIBL}|$ results as a function of $\mathrm{W}_{\mathrm{FIN}}$ and $\mathrm{L}$. A small subthreshold slope degradation is obtained with channel shortening. For [110]NWs with $\mathrm{W}_{\text {FIN }}$ of $25 \mathrm{~nm}, \mathrm{~S}$ is lower than $88 \mathrm{mV} / \mathrm{dec}$ down to $\mathrm{L}$ $=15 \mathrm{~nm}$. Through both $\mathrm{S}$ and |DIBL|, it is observed approximately constant dependence with $\mathrm{W}_{\mathrm{FIN}}$ for $\mathrm{L}=100 \mathrm{~nm}$ and $60 \mathrm{~nm}$, reduced SCE for narrower NWs for $\mathrm{L}=30 \mathrm{~nm}$ and that both [110]- and [100]-NWs exhibit similar results, as predicted by the logarithmic scaled curves in Fig. 3. Besides, $|\mathrm{DIBL}|$ is lower than $100 \mathrm{mV} / \mathrm{V}$ for [110]-oriented NWs with $\mathrm{W}_{\mathrm{FIN}}=25 \mathrm{~nm}$ and $\mathrm{L}$ down to $15 \mathrm{~nm}$.

Fig. 6 shows the results for the total resistance $\left(\mathrm{R}_{\mathrm{T}}=\right.$ $\left.\mathrm{V}_{\mathrm{DS}} / \mathrm{I}_{\mathrm{DS}}\right)$ as a function of the inverse of the $\mathrm{NW}$ gain $(\beta)$, for [110] and [100]-NWs, $W_{\text {FIN }}$ of 15,30 and $65 \mathrm{~nm}, \mathrm{~V}_{\mathrm{DS}}=-40 \mathrm{mV}$ and $V_{\mathrm{GT}}=-1 \mathrm{~V}$. From these curves, $\mathrm{R}_{\mathrm{S}}$ is extracted following the Y-function method [12]. Good linearity of the data points is demonstrated by the solid lines, which lead to series resistance values around 140 and $360 \Omega . \mu \mathrm{m}$, for [110] and [100]-NWs, respectively. The linear curves observed in Fig. 6 cross the $y-$ axis at the same $R_{T} . W_{\text {eff }}$ value for all $W_{\text {FIN }}$ studied, indicating that $\mathrm{R}_{\mathrm{S}}$ scales with $\mathrm{W}_{\mathrm{FIN}}$ for the entire range of $\mathrm{L}$, from 100 down to $15 \mathrm{~nm}$.

The hole mobility as a function of the inversion carrier density $\left(\mathrm{N}_{\text {inv }}\right)$ extracted by split-CV technique [13] for $\mathrm{L}=$ $100 \mathrm{~nm}$ and $\mathrm{W}_{\mathrm{FIN}}=15 \mathrm{~nm}$ is shown in Fig. 7. The maximum mobility is found equal to 63 and $32 \mathrm{~cm}^{2} / \mathrm{V}$.s for standard and rotated NWs, respectively. Moreover, the inner figure shows that the $\mu_{\mathrm{eff}}$ ratio between both [110] and [100]-NWs is close to 2 , which agrees with the $\mathrm{I}_{\mathrm{ON}} / \mathrm{W}_{\text {eff }}$ results obtained in Fig. 4.

Fig. 8 presents $\mu_{\text {eff }}$ as a function of L (a), extracted by $\mathrm{Y}$ function method, and as a function of $\mathrm{W}_{\mathrm{FIN}}(\mathrm{b})$, extracted by split-CV technique, for several NWs, at $\mathrm{N}_{\text {inv }}$ of $0.8 \times 10^{13} \mathrm{~cm}^{-2}$. Standard NWs show strong $\mu_{\text {eff }}$ degradation for $\mathrm{L}<60 \mathrm{~nm}$ while rotated NWs present a constant, but lower, mobility down to $\mathrm{L}=30 \mathrm{~nm}$. Besides, $\mu_{\mathrm{eff}}$ shows improvements of up to $17 \%$ with $\mathrm{W}_{\mathrm{FIN}}$ reduction for [110]-NWs, while [100]-NWs
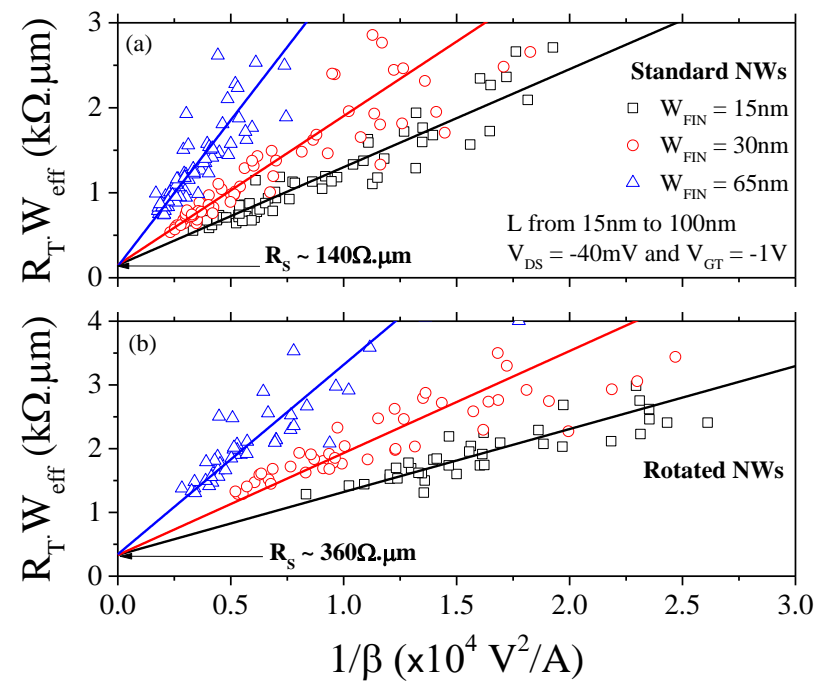

Fig.6. $\quad \mathrm{R}_{\mathrm{T}} \cdot \mathrm{W}_{\mathrm{eff}}$ as a function of $1 / \beta$ for several [110] (a) and [100]-NWs (b), at $\mathrm{V}_{\mathrm{DS}}=-40 \mathrm{mV}$ and $\mathrm{V}_{\mathrm{GT}}=-1 \mathrm{~V}$. 


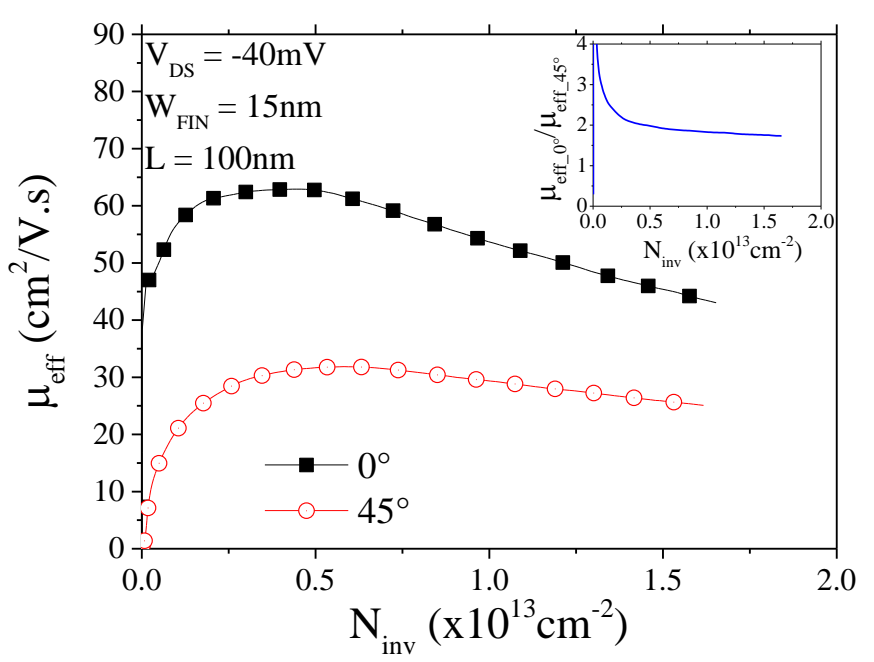

Fig.7. $\mu$ eff and $\mu$ eff_ $0 \% \mu$ eff_ $45^{\circ}$ as a function of $\mathrm{N}_{\text {inv }}$ for [110] and [100]NWs, $\mathrm{L}=100 \mathrm{~nm}$ and $\mathrm{W}_{\mathrm{FIN}}=15 \mathrm{~nm}$, at $\mathrm{V}_{\mathrm{DS}}=-40 \mathrm{mV}$.

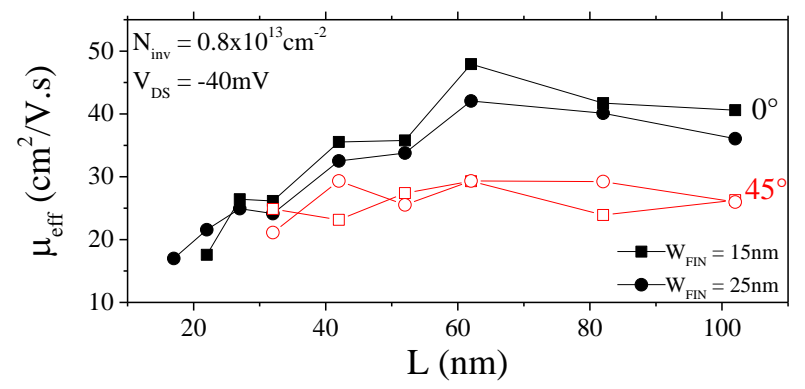

(a)

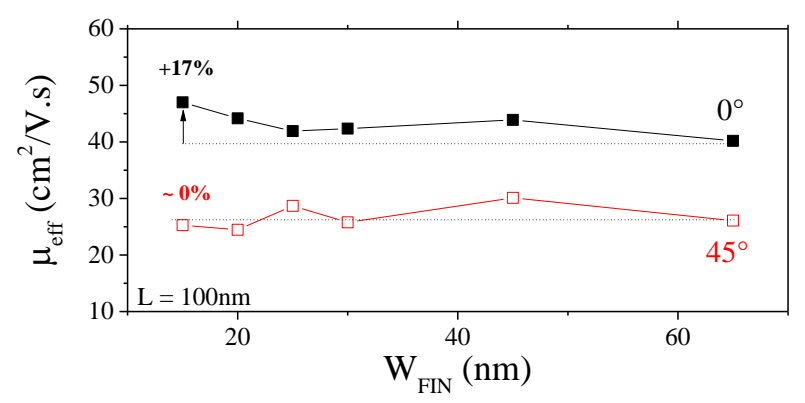

(b)

Fig.8. $\mu_{\text {eff }}$ as a function of $\mathrm{L}$ (a) and $\mathrm{W}_{\text {FIN }}$ (b) for several [110] and [100]-NWs, at $\mathrm{N}_{\text {inv }}=0.8 \times 10^{13} \mathrm{~cm}^{-2}$ and $\mathrm{V}_{\mathrm{DS}}=-40 \mathrm{mV}$.

show constant behavior, which is agreement with triple gate MOSFETs results [14].

\section{CONCLUSIONS}

Two levels stacked NWs present high $\mathrm{I}_{\mathrm{ON}} / \mathrm{W}_{\mathrm{FIN}}$ (up to $2500 \mu \mathrm{A} / \mu \mathrm{m}$ for [110]-NWs), although smaller $\mu_{\text {eff }}$ is expected for stacked p-NWs in comparison to $3 \mathrm{G}$ MOSFETs due to stronger top surface (100) contribution.

Despite complex source and drain engineering, the small values of series resistance extracted for [110]-stacked NWs are comparable to those obtained for advanced planar MOSFETs.
Excellent SCE control (small $\mathrm{V}_{\mathrm{TH}}, \mathrm{S}$ and DIBL degradations down to $15 \mathrm{~nm}$ gate length) have been obtained for both [110] and [100]-oriented NWs due to good electrostatic coupling and channel control provided by the sum of $\Omega$-Gate and GAA wires.

On the same way as for $3 \mathrm{G} \mathrm{NWs,} \mathrm{[110]} \mathrm{orientation} \mathrm{is} \mathrm{better}$ for p-type stacked NWs due to hole mobility improvements in (110)-oriented sidewalls.

\section{ACKNOWLEDGMENTS}

The authors would like to acknowledge the French Public Authorities from NANO 2017 program, CNPq and São Paulo Research Foundation (FAPESP) grants 2015/10491-7 and 2016/06301-0.

This work is also partially funded by the SUPERAID7 (grant $\mathrm{N}^{\circ}$ 688101) project.

\section{REFERENCES}

[1] J.-P. Colinge, "Multiple-gate SOI MOSFETs," Solid-State Electron., vol. 48, no. 6, pp. 897-905, Jun. 2004.

[2] K. J. Kuhn, "Considerations for Ultimate CMOS Scaling," IEEE Trans. Electron Devices, vol. 59, no. 7, pp. 1813-1828, Jul. 2012.

[3] R. Coquand et al., "Strain-induced performance enhancement of trigate and omega-gate nanowire FETs scaled down to 10nm Width," in 2012 Symposium on VLSI Technology (VLSIT), 2012, pp. 13-14.

[4] R. Coquand et al., "Scaling of high-k/metal-gate Trigate SOI nanowire transistors down to $10 \mathrm{~nm}$ width," in 2012 13th International Conference on Ultimate Integration on Silicon (ULIS), 2012, pp. 3740.

[5] S. Barraud et al., "Strained Silicon Directly on Insulator N- and PFET nanowire transistors," in 2014 15th International Conference on Ultimate Integration on Silicon (ULIS), 2014, pp. 65-68.

[6] M. Saitoh et al., "Short-channel performance and mobility analysis of $<110\rangle$ - and $<100>$-oriented tri-gate nanowire MOSFETs with raised source/drain extensions," in 2010 Symposium on VLSI Technology, 2010, pp. 169-170.

[7] H. Mertens et al., "Gate-all-around MOSFETs based on vertically stacked horizontal Si nanowires in a replacement metal gate process on bulk Si substrates," in 2016 IEEE Symposium on VLSI Technology, 2016, pp. 1-2.

[8] C. Dupre et al., " $15 \mathrm{~nm}$-diameter 3D stacked nanowires with independent gates operation: ФFET," in 2008 IEEE International Electron Devices Meeting, 2008, pp. 1-4.

[9] S. Barraud et al., "Vertically stacked-NanoWires MOSFETs in a replacement metal gate process with inner spacer and $\mathrm{SiGe}$ source/drain," in 2016 IEEE International Electron Devices Meeting (IEDM), 2016, p. 17.6.1-17.6.4.

[10] S. Takagi, A. Toriumi, M. Iwase, and H. Tango, "On the universality of inversion layer mobility in Si MOSFET's: Part II-effects of surface orientation," IEEE Trans. Electron Devices, vol. 41, no. 12, pp. 2363 2368, Dec. 1994

[11] J. Pelloux-Prayer et al., "Study of the piezoresistive properties of NMOS and PMOS $\Omega$-gate SOI nanowire transistors: Scalability effects and high stress level," in Electron Devices Meeting (IEDM), 2014 IEEE International, 2014, p. 20.5.1-20.5.4.

[12] G. Ghibaudo, "New method for the extraction of MOSFET parameters," Electron. Lett., vol. 24, no. 9, pp. 543-545, Apr. 1988.

[13] A. Ohata, M. Cassé, and S. Cristoloveanu, "Front- and back-channel mobility in ultrathin SOI-MOSFETs by front-gate split CV method," Solid-State Electron., vol. 51, no. 2, pp. 245-251, Feb. 2007.

[14] J. Pelloux-Prayer et al., "Transport in TriGate nanowire FET: Crosssection effect at the nanometer scale," in 2016 IEEE SOI-3DSubthreshold Microelectronics Technology Unified Conference (S3S), 2016, pp. 1-2. 